\title{
Document Version Uniform Resource Locator
}

National Cancer Institute

\section{Source}

National Cancer Institute. Document Version Uniform Resource Locator. NCI Thesaurus. Code C93821.

A complete reference to a website (including http://) from which the document contents can be retrieved. 